\title{
Missed Diagnosis of a Heterotopic Pregnancy with Tubal Rupture: A Case Report
}

\author{
Sharma B \\ Department of Obs/Gyne, KIST Medical College Hospital, Lalitpur, Nepal
}

We report a combined intra-uterine and ruptured tubal pregnancy following ovulation induction by clomiphene citrate(CC).She was a 35 year old multigravida who presented with a ruptured tubal pregnancy and underwent right salphingectomy. Three months later, she presented with amenorrhea from the time of operation and an intra-uterine pregnancy was confirmed. Previous ultrasound at her initial presentation, did not reveal an intra-uterine pregnancy. The second ultrasound dating indicated that the intra-uterine conception had occurred before the tubal pregnancy was diagnosed. Therefore, a high index of suspicion for heterotopic pregnancy is needed in woman taking ovulation inducing drugs.

Keywords: Clomiphene citrate, heterotopic pregnancy, ruptured tubal pregnancy

\section{INTRODUCTION}

Heterotopic pregnancy (HP) is defined as the simultaneous occurrence of an intra-uterine and ectopic pregnancy. ${ }^{1}$ It is a rare entity, with a difficult pre-operative diagnosis and is potentially dangerous for the mother and the intra-uterine pregnancy. ${ }^{2}$ Delay in diagnosing the condition and failure to proceed quickly with the requisite anesthesia and surgery can jeopardize both maternal well-being and survival of the intra-uterine fetus. ${ }^{3}$ The estimated incidence of HP is accepted between $1 / 30,000$ and $1 / 8,000$ pregnancies. The risk has increased after the widespread use of ovulation induction therapies and assisted reproductive techniques. ${ }^{4}$ Clomiphene citrate (CC) is the treatment of choice in the management of woman with an-ovulation and infertility who are normally estrogenized. CC induction can cause multiple follicular development, ovarian hyperstimulation, and multiple pregnancy. ${ }^{5}$ Preclinical and clinical abortions are increased only slightly by CC use, compared to spontaneous pregnancy. Conception and preclinical abortions are related to endometrial thickness prior to ovulation. ${ }^{6} \mathrm{CC}$, which increases the rate of twinning, could be associated with a HP rate of $1 / 900 .^{7}$

\section{CASE}

A 35 year old gravida 3, para 2 presented to the emergency ward at KIST Medical College Hospital, on 28.08.10 with a one-week history of lower abdominal pain which had increased since six hours. There was no vaginal bleeding. She had amenorrhea of 5 weeks and 5 days duration. There was no significant past medical or surgical history. She had a history of secondary subfertility and was taking clomiphene citrate for 2 months before conception. On examination, her general condition was stable and vitals were within normal limits. There was tenderness over the hypogastrium and right iliac fossa. On vaginal examination, cervical motion tenderness and generalized

\section{CORRESPONDENCE}

Dr. Bandana Sharma, MD

Associate Professor

Department of obstetrics/gynecology

KIST Medical College, Imadol, Lalitpur, Nepal

Phone: 9841341744

E-mail: drbandanamd@gmail.com 
pelvic tenderness was present. The uterine size could not be assessed due to guarding of lower abdominal muscles. Urine pregnancy test was positive. Hemoglobin concentration was $8.4 \mathrm{gm} / \mathrm{dl}$. The clinical diagnosis of a ruptured ectopic pregnancy was made. An emergency ultrasonogram revealed findings suggestive of a ruptured right ectopic pregnancy with hemoperitoneum . Emergency exploratory laparotomy was performed.

During operation, hemoperitoneum of approximately half-litre was found, together with a ruptured right tubal-ampullary ectopic pregnancy. The uterus was bulky, left tube and both ovaries were normal. Suction of hemoperitoneum, right sided salpingectomy and peritoneal lavage was carried out. Two units of blood transfusion were given. Post-operative recovery was uneventful. Histo-pathological examination of the excised tube confirmed the presence of chorionic villi.

On 25.11.2010 (three months after the laparotomy) she presented to the gynecology out-patient department complaining of continuing amenorrhea since the time of laparotomy. On abdominal examination, uterus was 18 weeks size. An ultrasound examination revealed a normal, single, intra-uterine pregnancy, with biometry suggestive of 18 weeks gestation, which corresponded to her last menstrual period before laparotomy. In other words, the uterine pregnancy coexisted when tubal pregnancy was diagnosed and treated. Most probably the intrauterine pregnancy was missed during previous ultrasonogram. Unfortunately, she failed to come for follow-up later.

\section{COMMENT}

The co-existence of intra-uterine and extrauterine pregnancy, also known as heterotopic pregnancy, was previously a rare phenomenon. Estimated world-wide incidence in a spontaneous conception was $1 / 30,000$ in the late 1980 's. ${ }^{8}$ Due to widespread use of ovulation induction drugs such as clomiphene and other assisted reproductive techniques; incidence has now been thought to be more frequent. ${ }^{9,10}$ It has recently been reported to be as high as $0.75-1.3 \%,{ }^{11,5}$ or even higher if there has been pre-existing tubal damage.

The risk of ectopic pregnancy increases significantly after pelvic inflammatory disease. Mainly chlamydial infections, ${ }^{12}$ widespread use of IUDs, ${ }^{13}$ microsurgical repair of tubal damage caused by pelvic inflammatory disease are considered to be serious risk factors. ${ }^{14}$

In cases of assisted conception the incidence of ectopic pregnancy is increased many times and a mean rate of
$5 \%$ has been reported. ${ }^{15}$ The increase in the risk is due to ovulation induction leading to multifollicular development and multiple embryo transfer. Also high estrogen concentrations after ovulation induction may disturb the tubal transport. ${ }^{16,17}$ Clomiphene citrate is the treatment of choice in women with ovulatory-disorders who have normal estrogen levels. ${ }^{5}$ After CC induction of ovulation the rate of multiple pregnancy and HP are increased. ${ }^{6,18}$ Although several reports have suggested that the rate of ectopic pregnancy is increased following CC induction or when CC is used in combination with HMG for in-vitro fertilization, contrarily some authors suggested that these studies were not controlled for endometriosis and tubal disease. $^{6}$

Heterotopic pregnancy is difficult to diagnose and is a potentially dangerous condition for both the mother and the intra-uterine pregnancy. In an isolated ectopic pregnancy, sonographic evidence of an empty uterine cavity combined with a human chorionic gonadotrophin (hCG) level higher than $1,500 \mathrm{mIU} / \mathrm{ml}$ is the principal indicative factor. ${ }^{1}$ In the case of combined intra-uterine and extra-uterine pregnancy the early diagnosis of ectopic pregnancy is thus almost impossible. Therefore, it is not surprising that most heterotopic pregnancies are diagnosed only after tubal rupture and hemorrhagic shock. In HP, despite the tubal rupture and hemorrhagic shock, the prognosis for the intra-uterine pregnancy continuation rates of $75.6 \%$ were reported by Reece et al $^{19}$ and $60 \%$ by Molloy et al ${ }^{17}$ In our case the pregnancy was unharmed upto 18 weeks of gestation and after that the patient failed to follow up.

\section{CONCLUSIONS}

Heterotopic pregnancy can occur in the absence of any predisposing risk factors, and the detection of an intrauterine pregnancy does not exclude the possibility of the simultaneous existence of an ectopic pregnancy. Hence, in all patients of reproductive age, even in the presence of an intra-uterine pregnancy, a complete review of the whole pelvis including adnexa should be done at the time of ultrasound to rule out the presence of a heterotopic pregnancy. In our case, intra-uterine pregnancy was missed during emergency USG. The reason could be because of strong clinical suspicion of ectopic pregnancy and presence of hemoperitoneum where USG overlooked intra-uterine pregnancy. A high index of suspicion and strict follow-up of the patient post-operatively could have led to an earlier diagnosis. 


\section{REFERENCES}

1. Thakur R, EI-Menabawey M. Combined intra-uterine and extrauterine pregnancy associated with mild hyperstimulation syndrome after clomiphene ovulation induction. Hum Reprod. 1996;11(7):1583-4.

2. Kably AA, Alarcon JW, Garcia JF, Reyes CH. Early diagnosis of heterotopic pregnancy with viability of the intrauterine fetus. Report of two cases and review of the literature. Ginecol Obstet Mex.1995 63:346-8.

3. Chandra PC, Schiavello HJ, Briggs SL, Samuels JD. Heterotopic pregnancy with term delivery after rupture of a first-trimester tuba pregnancy. A case report. J Reprod Med.1999;44(6):556-8.

4. Cenk SN, Yardim T. Live birth of healthy twins after a heterotopic tubal and intrauterine twin pregnancy in a woman who was stimulated with clomiphene citrate. Fertil Steril. 2003;80(5):1265-7.

5. Kousta E, White DM, Franks S. Modern use of clomiphene citrate in induction of ovulation. Hum Reprod Update.1997;3(4):359-65.

6. Dickey RP, Holtkamp DE. Development, pharmacology and clinical experience with clomiphene citrate. Hum Reprod Update.1996;2(6):483-506.

7. Bello GV, Schonholz D, Moshirpur J, Jeng DY, Berkowitz RL Combined pregnancy: the Mount Sinai experience. Obstet Gynecol Surv.1986;41(10):603-13.

8. DeVoe RW, Pratt JH. Simultaneous intrauterine and extrauterine pregnancy. Am J Obstet Gynecol.1948;56(6):1119-26.

9. Ceci O, Caradonna F, Loizzi P et al. Ultrasound diagnosis of heterotopic pregnancy with viable fetuses. Eur J Obstet Gynecol Reprod Biol. 1993;52(3):229-31.
10. Berliner I, Mesbah M, Zalud I, Maulik D. Heterotopic triplet pregnancy. Report of a case with successful twin intrauterine gestation. J Reprod Med. 1998;43(3):237-9.

11. Lemus JF. Ectopic pregnancy an update. Curr Opin Obstet Gynecol. 2000;12(5):369-75.

12. Brunham RC, Binns B, McDowell J, Paraskevas M. Chlamydia trachomatis infection in women with ectopic pregnancy. Obstet Gynecol. 1986;67(5):722-6.

13. Russell JB. The etiology of ectopic pregnancy. Clin Obstet Gynecol.1987;30(1):181-90.

14. Lavy G, Diamond MP, DeCherney AH. Ectopic pregnancy: its relationship to tubal reconstructive surgery. Fertil Steril.1987;47(4):543-56.

15. Yovich JL, McColm SC, Turner SR, Matson PL. Heterotopic pregnancy from in vitro fertilization. J In Vitro Fert Embryo Transf 1985;2(3):143-50.

16. Yovich JL, Stanger JD, Tuvic A, Hahnel R. Combined pregnancy after gonadotrophin therapy. Obstet Gynecol.1984;63(6):855-8.

17. Molloy D, Deambrosis W, Keeping D, Hynes J, Harrison K, Hennessey J. Multiple-sited (heterotopic) pregnancy after in vitro fertilization and gamete intrafallopian transfer. Fertil Steril.1990;53(6):1068-71.

18. Glassner MJ, Aron E, Eskin BA. Ovulation induction with clomiphene and the rise in heterotopic pregnancies. A report of two cases. J Reprod Med.1990;35(2):175-8.

19. Reece EA, Petrie RH, Sirmans MF, Finster M, Todd WD. Combined intrauterine and extrauterine gestations: a review. Am J Obstet Gynecol.1983;146(3):323-30. 